\title{
THE PROFITABILITY OF MOMENTUM STRATEGIES: EMPIRICAL EVIDENCE FROM DAMASCUS SECURITIES EXCHANGE (DSE)
}

(D) Oubay Mahmoud ${ }^{1+}$
iD Almougheer I.
Wardeh $^{2}$

(2)

\section{Article History}

Received: 26 September 2017 Revised: 30 November 2017 Accepted: 23 January 2018 Published: 23 February 2018

\section{Keywords}

Momentum strategy

Contrarian strategy

Efficient market hypothesis

Market model

Damascus securities exchange.

\author{
${ }^{\prime}$ Lecturer at Faculty of Economics, Department of Finance \&' Banking, \\ Tishreen University, Syria \\ Email:btemmana2000@yahoo.com \\ ${ }^{2}$ Master student at Faculty of Economics, Department of Finance \& Banking, \\ Tishreen University, Syria
}

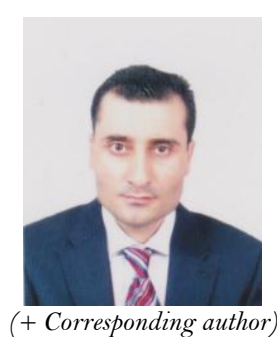

ABSTRACT

The purpose of this study is to examine the profitability of Momentum based- trading strategies and investigate the causes of such profitability in Damascus Securities Exchange (DSE) market. The study analyzed 16 Momentum strategies based on full rebalancing and equally weighted techniques using monthly data from January 2010 to December 2016. The findings of the study showed low but significant Momentum effect, where the returns of Momentum portfolios were statistically positive only in 1 out of 16 strategies. Our findings suggest that Momentum strategy is applicable for winner portfolios whereas contrarian strategy is more appropriate for loser portfolios. We also adopted Market Model in order to investigate the possible risk-based explanations of Momentum profits, but we found that market risk is unable to explain the Momentum profitability in DSE market.

Contribution/Originality: This study contributes in the literature related to financial market efficiency by finding the link between Momentum strategies and abnormal returns. Consequently, providing an evidence about the link between Momentum effect and market efficiency in emerging markets.

\section{INTRODUCTION}

The Efficient Market Hypothesis (EMH), under its weak form, asserts that future returns cannot be predicted by using past returns. However, two anomalies contradict this hypothesis and are considered as the most puzzling anomalies in the stock markets. These anomalies are Momentum effect of Jagadeesh and Titman (1993;2001) and Contrarian effect of De Bondt and Thaler (1985;1987).

Momentum is a term used in the behavioral finance literature to characterize stock price continuation or persistence in the short and medium terms (Al-Muhairi, 2011). It means that past winners are achieving positive returns in the future and past losers are achieving negative returns in the future over short and intermediate horizons of 3 to 12 months (Jagadeesh and Titman, 1993). According to Jagadeesh and Titman (1993) Momentum strategy suggests buying stocks with high performance (high returns) over the past 3 to 12 months and selling stocks with low performance (low returns) over the same time-period. This strategy will enable portfolio manager to make abnormal profits.

On the contrary of Momentum strategy, Contrarian strategy or long-run overreaction hypothesis of De Bondt and Thaler $(1985 ; 1987)$ suggests that past winners are achieving negative returns in the future and past losers are 
achieving positive returns in the future over a long horizon of 3 to 5 years. Therefore, this strategy suggests that, on average, prior losers outperform prior winners in the long-term (Cheng and $\mathrm{Wu}, 2010$ ). Thus, portfolio manager can earn abnormal profits by buying past losers and selling past winners.

This study will focus on testing the Momentum effect in Damascus Securities Exchange (DSE) market and thus its weak form efficiency. DSE market is a young and nascent stock market that was established and started trading on $10^{\text {th }}$ March 2009. Its weighted price index (DWX) was launched on 31/12/2009. A few number of studies have tested the weak form efficiency of DSE market by testing the random walk of returns. Both studies of Al-Ahmad (2012) for the period (2009-2011) and Abbas (2014) for the period (2009-2014) found that DSE market is inefficient, in other words, its returns do not follow random walk.

This evidence of inefficiency of DSE market in previous studies mentioned above was the prime motive for us to check for the anomalies that exist in this market. The second motive was the fact that most previous studies about Momentum strategies focused on the stock markets in developed countries, leaving the developing countries' stock markets awaiting such study. The last and the most important motive was the lack of studies that investigated Momentum effect in DSE market.

The aim of this study is of three folds. First investigating whether the Momentum effect existed in DSE market over seven-year period from 2010 through 2016. Second, contributing to the debate on efficient markets whereby finding profitable Momentum strategies in DSE market will give a strong evidence of inefficiency in DSE market from the weak form. Third, examining the risk based-factors influencing profitability of Momentum strategies in the DSE.

The remaining of this paper is organized as follows: section two reviews the previous literature on Momentum effect; section three presents the data and methodology applied; section four shows the results and discussion; and section five concludes.

\section{LITERATURE REVIEW}

Jagadeesh and Titman (1993) investigated the Momentum effect using data from US market (NYSE and AMEX stocks) during the period (1965-1989). The formation periods considered for selecting stocks were based upon their returns over the past 3, 6, 9, 12 months. The holding periods were also the same, consequently they tested 16 different strategies. They found that Momentum strategies yield positive abnormal returns (about $1 \%$ per month), and the most successful Momentum strategy is selecting stocks based on their returns over the past 12 months and then holds the portfolio for 3 months. This strategy yields $1.31 \%$ per month. Furthermore, they found that these abnormal returns could not be explained by market risk.

Since the work of Jagadeesh and Titman (1993) numerous researchers have documented the Momentum effect across different markets and time-periods. Rouwenhorst (1998) has found evidence on Momentum in 12 European markets during the period (1978-1995). Moreover, Rouwenhorst (1999) found evidence on Momentum in 17 of 20 emerging markets over the period 1982 - 1997. Chui et al. (2001) have reported similar evidence in favor of the Momentum effect in 9 emerging markets. Griffin et al. (2003) also found statistically significant Momentum profits across the world in both good and bad business cycle. Kolobaric and Khatabakhsh (2011) investigated the international profitability of Momentum strategies in 45 countries chosen from different continents during the time-period 1995 - 2010, they found positive abnormal returns over 3 to 12 months. Moreover, they found that Capital Asset Pricing Model (CAPM) and the Fama and French three-factor model could not explain these abnormal returns.

Considering country-level studies, Hon and Tonks (2001) investigated the presence of abnormal returns by using Momentum strategies in the UK stock market during the period 1955-1996. They found profitable Momentum strategies, but those are only apparent over certain time-periods. They also used Market Model in order to investigate whether beta risk explains these abnormal profits, but found that these abnormal profits could 
not be explained by market risk. Similarly, Siganos (2004) aimed to examine the Momentum effect and its causes using data from London stock exchange from January 1975 to October 2001. His results showed that Momentum strategies can generate abnormal returns of about $1 \%$ per month. In addition, he found that Momentum profits couldn't be explained by market risk. Likewise, Annerstedt and Schonstrom (2006) examined the profitability of Momentum strategies on the Nordic stock markets between April 1991 and April 2006. They found that Momentum portfolios are significantly profitable with 3-12 months horizon. Sondergaard (2010) tested whether the Momentum effect has existed on the Danish stock market over the period 1996-2009. They found that all 16 strategies examined were significantly positive. They also investigated the possible explanations for the observed Momentum phenomenon by using Fama and French three-factor model, but they found that none of the risk measures was able to explain this phenomenon. Cheng and Wu (2010) investigated the profitability of Momentum trading strategies and examined its sources in Hong Kong for the period from January 1980 to December 1999. They found that Momentum portfolios are significantly profitable in the intermediate term, but the profits were insignificant after risk being adjusted using Chordia and Shivakumar (2006) model. Luxianto (2010) explored the effectiveness of Momentum or contrarian strategy in Indonesian stock exchange for the period from January 2000 to December 2009. The results showed that Momentum strategy was effectively applicable for winner stock, whereas contrarian strategy was more effective for loser stock. Al-Muhairi (2011) investigated the short-term continuation for stocks listed in the United Arab Emirates stock market and looked for its possible explanations over the period from January 2001 to June 2006. He found that winner portfolios tend to outperform loser portfolios of stocks over pre- and post-formation periods of 3 to 12 months. Moreover, he found that market risk, based on CAPM and the Fama and French model are unable to explain the performance of Momentum returns. Polak and Ejaz (2012) examined the profitability of Momentum strategies in Bombay stock exchange using monthly stocks prices of top one hundred companies' index. They found a strong evidence of Momentum effect and the abnormal returns were due to the price Momentum strategies. Habib-Ur-Rahman and Mohsin (2012) investigated the Momentum effect in emerging market (Karachi stock exchange) by taking a sample of 300 companies from 1999 to 2007 . He found a Momentum effect in 1 out of 16 applied strategies. Vas and Absalonsen (2014) examined the Momentum effect on the Oslo stock exchange. They found a strong Momentum effect. They have also applied rational model for risk factors and concluded that Fame and French 3-factor and CAPM do not explain the effect of Momentum. Khan et al. (2016) investigated the Momentum effect in Karachi stock exchange by taking a sample of 83 companies listed at KSE-100 Index from 2007 to 2014. They found Momentum effect in four out of 16 applied strategies. The study reported low and significant Momentum effect at Karachi stock exchange.

Our study contributes to the literature related to financial market efficiency by finding the link between Momentum strategies and abnormal returns. Consequently, providing an evidence about the link between Momentum effect and market efficiency in emerging markets. This is done by applying the methodology of Jagadeesh and Titman (1993) in a young and nascent stock market "DSE market" and thus to giving an evidence of efficiency/or inefficiency of this market. And testing whether Momentum strategies, buying the best performed stocks in the past, and/or selling the worst performed stocks in the past, are profitable in DSE market.

\section{DATA AND METHODOLOGY}

\subsection{Population and Data}

The population for the study is all listed companies of Damascus Securities Exchange (DSE) market. Therefore, all 24 companies listed in the DSE as in January 2017 are considered. Table (1) shows the companies under study. 
Table-1. Population of the study

\begin{tabular}{|c|c|c|}
\hline Companies & Symbol & Listing Date \\
\hline \multicolumn{3}{|l|}{ Banks Sector: } \\
\hline Al Baraka Bank - Syria & BBSY & $15 / 10 / 2014$ \\
\hline Arab Bank - Syria & ARBS & $2 / 3 / 2009$ \\
\hline Bank Alsharq & SHRQ & $2 / 12 / 2010$ \\
\hline Bank Audi Syria & BASY & $5 / 3 / 2009$ \\
\hline Bank of Jordan Syria & BOJS & $23 / 6 / 2010$ \\
\hline Bank of Syria and Overseas & BSO & $5 / 3 / 2009$ \\
\hline Banque Bemo Saudi Fransi & BBSF & $2 / 2 / 2009$ \\
\hline Byblos Bank Syria & BBS & $17 / 11 / 2009$ \\
\hline Cham Bank & $\mathrm{CHB}$ & $21 / 5 / 2014$ \\
\hline Fransabank Syria & FSBS & $5 / 1 / 2011$ \\
\hline Qatar National Bank - Syria & QNBS & $8 / 4 / 2010$ \\
\hline Syria Gulf Bank & SGB & $28 / 7 / 2010$ \\
\hline Syria International Islamic Bank & SIIB & $2 / 6 / 2009$ \\
\hline The International Bank for Trade \& Finance & IBTF & $30 / 3 / 2009$ \\
\hline \multicolumn{3}{|l|}{ Insurance Sector: } \\
\hline$\overline{\text { Al-Aqeelah Takaful Insurance }}$ & ATI & $22 / 8 / 2010$ \\
\hline National Insurance Company & NIC & $7 / 6 / 2010$ \\
\hline Solidarity Alliance Insurance & SAIC & $27 / 7 / 2011$ \\
\hline Syria International Insurance - Arope & AROP & $7 / 4 / 2010$ \\
\hline Syrian Kuwaiti Insurance Company & SKIC & $13 / 5 / 2012$ \\
\hline United Insurance Company & UIC & $24 / 6 / 2009$ \\
\hline \multicolumn{3}{|l|}{ Services Sector: } \\
\hline Alahliah Co. for Transport & AHT & $2 / 3 / 2009$ \\
\hline United Group for Publishing Advertising and Marketing & $\mathrm{UG}$ & $3 / 2 / 2009$ \\
\hline \multicolumn{3}{|l|}{ Industrial Sector: } \\
\hline Alahliah Vegetable Oil Company & AVOC & $10 / 6 / 2009$ \\
\hline \multicolumn{3}{|l|}{ Agricultural Sector: } \\
\hline Agricultural Engineering Co for Investments - Nama'a & NAMA & $13 / 4 / 2009$ \\
\hline Total $=24$ companies & & \\
\hline
\end{tabular}

The monthly market close price of DSE market index (DWX), monthly close prices and cash dividends of individual stocks listed on DSE market from January 2010 to December 2016 were obtained from the DSE website (http://www.dse.sy/index.php). Using monthly close prices, monthly stock returns were calculated as follows (Hon and Tonks, 2001; Siganos, 2004):

$$
R_{i, t}=\ln \frac{\left(\boldsymbol{P}_{\boldsymbol{i}, \boldsymbol{t}}+\boldsymbol{d}_{\boldsymbol{i}, \boldsymbol{t}}\right)}{\boldsymbol{P}_{\boldsymbol{i}, \boldsymbol{t}-\mathbf{1}}}
$$

Where $R_{i, t}$ is the natural logarithmic return of security i in month $t, P_{i, t}$ : is the close price which is the last traded price of security i in month $t, d_{i, t}$ : is the cash dividend of security $\mathrm{i}$ that have been paid between month $\mathrm{t}-1$ and month $\mathrm{t}, P_{i, t-1}$ : is the last traded price of security i in month $\mathrm{t}-1$.

The problem in calculating monthly returns is that the close prices and dividends are not modified to events such as stocks fragmentation. Therefore, researchers modified close prices by multiplying the prices after fragmentation by the number of new stocks ${ }^{1}$. The same procedure followed with regard to dividends.

\subsection{Calculating Momentum Portfolios Profitability}

Our methodology builds on the procedure suggested by Jagadeesh and Titman (1993). We have formed the Momentum portfolios using the following steps:

\footnotetext{
1i.e. If one stock price was 500 s.p. before fragmentation, and fragmented into five stocks with value 100 s.p. for each stock, then we multiply the new price by the
} number of new stocks: $100 * 5=500$. 


\section{Step 1: Formation and Holding Periods:}

The first step is deciding on the length of the formation and the holding periods. The formation period or the ranking period (Siganos, 2004) which is given the notation $J$, is the period that the stocks are ranked in ascending order according to their monthly returns over the past J-months (Sondergaard, 2010; Vas and Absalonsen, 2014). This period, in this study, is 3, 6, 9 or 12 months. The holding period or the test period (Siganos, 2004; Khan et al., 2016) also called the investment period (Vas and Absalonsen, 2014) and also known as the evaluation period (Luxianto, 2010) which is given the notation $\mathrm{k}$, is the period during which the investor keeps his investment (Annerstedt and Schonstrom, 2006). This period, in this study, is also 3, 6, 9 or 12 months. Therefore we have four formation periods ( $\mathrm{J}=3,6,9,12$ months), and four holding periods ( $\mathrm{K}=3,6,9,12$ months). The combination of different formation periods $(\mathrm{J})$ with different holding periods $(\mathrm{K})$ will give us 16 different Momentum strategies $(4 * 4)$.

An investment or trading strategy based on the monthly returns from the past J-months and held for Kmonths will be referred to as the "J-months/K-months strategy" (Annerstedt and Schonstrom, 2006). Figure 1 provides a graphic overview of the different Momentum strategies applied in our study.

The Momentum portfolios were formed immediately after the formation period, without skipping any period following previous studies as Khan et al. (2016).

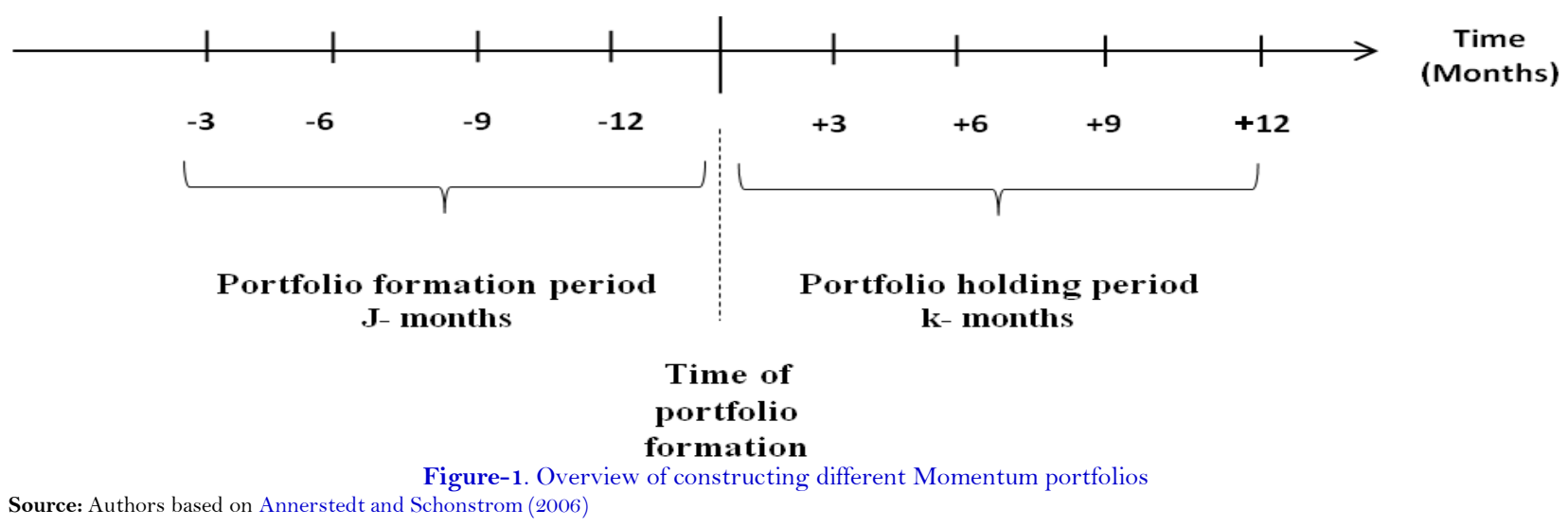

Step 2: Full versus partial rebalancing (Overlapping versus Non-Overlapping Periods):

The second step is deciding on which of these two methods to be adopted in constructing portfolios: full rebalancing method (i.e. non-overlapping period) or partial rebalancing method (i.e. overlapping period). With full rebalancing method, the portfolios are formed immediately after the formation period; whereas in partial rebalancing method, the portfolios are formed or rebalanced monthly (Sondergaard, 2010). Figure 2 shows the difference between these two methods.

In this study, we used the full rebalancing method (or non-overlapping period) following previous studies (i.e. (Hon and Tonks, 2001; Siganos, 2004; Sondergaard, 2010)). 
Months

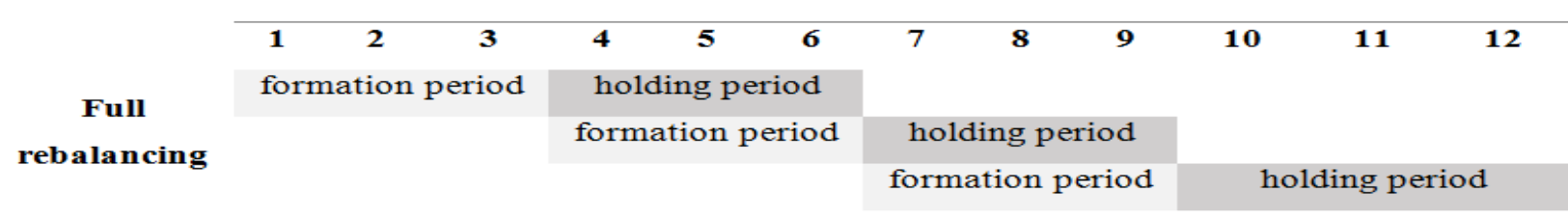

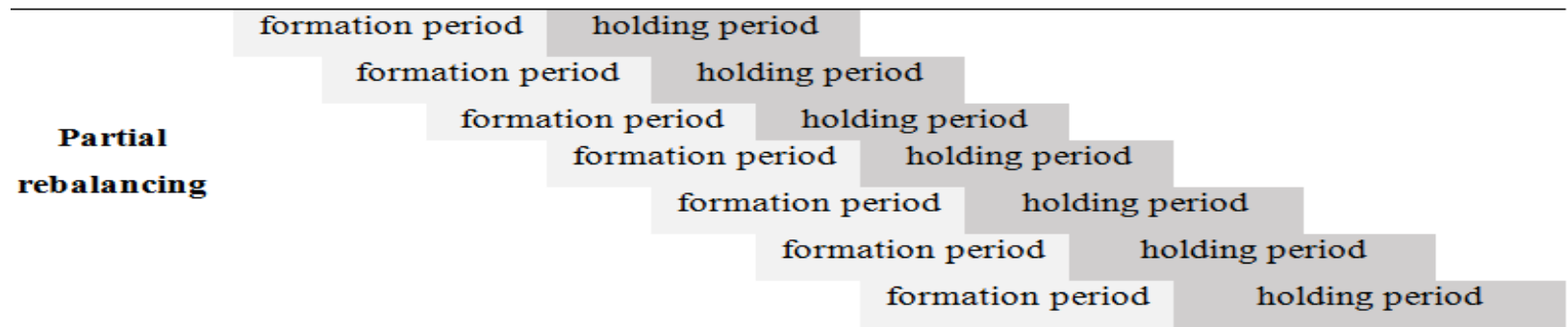

Figure-2. Full versus partial rebalancing

Source: (Sondergaard, 2010; Vas and Absalonsen, 2014; Khan et al., 2016).

\section{Step 3: Winners and Losers Portfolios Formations}

The procedure followed in constructing portfolios is the one adopted by Jagadeesh and Titman (1993) whereby at the end of each formation period (or at the beginning of each holding period), all of the stocks are ranked in ascending order according to their past J-month cumulative returns (their returns during formation period). The formation period cumulative returns are calculated as follows (Siganos, 2004; Khan et al., 2016):

$$
C R_{i}(J)=\sum_{t=1}^{J} R_{i, t}
$$

Where $C R_{i}(J)$ is the cumulative return of stock i during the formation or rank period; J expressed in the number of months; and $R_{i, t}$ is the natural logarithmic return of security $\mathrm{i}$ in month $\mathrm{t}$ as defined in equation (1).

Then, based on the ranking, three equally weighted portfolios are formed according to the quintile return values: Top 30\%, medium 40\%, and bottom 30\% (following Rouwenhorst (1999)). This small number of portfolios is due to the small number of stocks listed in DSE market, and also to avoid probability of having one security in one portfolio.

The portfolios that comprise the highest $30 \%$ of the past J-month cumulative returns are called the "Winners Portfolios" and denoted "W", whereas the portfolios that comprise the lowest 30\% of the past J-month cumulative returns are called the "Losers Portfolios" and denoted "L". For each trading or investment strategy among 16 strategies, the $\mathrm{W}$ and $\mathrm{L}$ constructed portfolios are held for $\mathrm{K}$ months (the holding period) (Annerstedt and Schonstrom, 2006; Cheng and $\mathrm{Wu}, 2010)$. It should be noted that Stocks with missing or zero monthly returns during the formation period are excluded from the Momentum portfolio (see Cheng and Wu (2010)).

\section{Step 4: Calculating the Return of Portfolios}

The return of the portfolios during the holding period, giving equally weights to all stocks, is calculated as follows (Vas and Absalonsen, 2014; Khan et al., 2016):

$$
C R_{P}(K)=\frac{\sum_{i=1}^{N} C R_{i}(k)}{N}
$$

Where $C R_{P}(K)$ is the return of the portfolio $\mathrm{P}$ for the holding period $\mathrm{K} ; C R_{i}(k)$ is holding period cumulative return of stock i which is calculated as follows:

$$
C R_{i}(K)=\sum_{t=1}^{K} R_{i, t}
$$


$\mathrm{N}$ is the number of securities or stocks in each portfolio, and $\mathrm{K}$ is the number of months of holding period. Based on the return of winners and losers portfolios, Momentum portfolio or "Zero-Cost Portfolio"[also known as "Buy-Sell Portfolio" or "Winners-Losers Portfolio"] is constructed by calculating the difference between Winners Portfolio's return and Losers Portfolio's return as follows (Vas and Absalonsen, 2014; Khan et al., 2016):

$$
C R_{M}=C R_{W}-C R_{L}
$$

Where $C R_{M}$ is the return of Momentum portfolio; $C R_{W}$ is the return of winners portfolio; and $C R_{L}$ is the return of losers portfolio.

The average return of every Momentum strategy is calculated by taking the average return of all Momentum portfolios formed throughout this strategy during the sample period (2010-2016) and divided it by the number of holding periods $\mathrm{H}$ (Vas and Absalonsen, 2014; Khan et al., 2016):

$$
M R=\frac{\sum_{t=1}^{T} C R_{M}(K)}{H}
$$

Where MR is e average return of Momentum strategy, and $\mathrm{H}$ is the number of holding periods (or rebalancing times).

The previous calculations are done for each Momentum strategy.

\section{Step 5: Testing the Profitability of Momentum Strategies}

Taking into account the fact that Momentum strategies are zero-cost, the returns of Momentum strategies is compared with benchmark zero to test the profitability of Momentum strategies.

The null hypothesis (Ho): the return of Momentum portfolio is equal to zero and investors are not able to make abnormal returns by using the historical information (past returns), which implies that DSE market is an efficient market from the weak form.

$$
\mathrm{H}_{0}: C R_{M}=\mathrm{o}
$$

The alternative hypothesis ( $\mathrm{H} 1$ ): the return of Momentum portfolio is different from zero (DSE market is not efficient). Thus, either Momentum effect or Contrarian effect appears. In other words, if the Momentum portfolio return is positive, then the momentum effect is supported. When it is negative, this implies that Contrarian effect is supported.

$$
\mathrm{H}_{1}: C R_{M} \neq \mathrm{O}
$$

One sample test (t-test) and Kolmogorov-Smirnov test have been used to test the null hypothesis after testing the normality distribution of the return series of Momentum strategies. Kolmogorov-Smirnov test of normality has applied using SPSS V.22 package. When the p. value is more than 0.05, there is evidence to accept $\mathrm{H}_{0}$. If the p-value is less than 0.05 , there is evidence to reject the $\mathrm{H}_{0}$ in favor of $\mathrm{H}_{1}$. That is, there is evidence of Momentum in DSE market. Thus, the Momentum portfolios will generate significant abnormal profits.

\subsection{Sources of Momentum Profitability}

For Momentum strategies that reported significant abnormal returns, we attempted to investigate the possible risk-based explanations of these abnormal returns. We adopted the Market Model or Single-Index Model in order to estimate the Beta values (Systematic Risk) of Momentum portfolios (see e.g. Hon and Tonks (2001)). The use of market model instead of CAPM model is due to unavailability of data related to the return of risk-free security in Syria.

The market model is:

$$
C R_{P, t}=\alpha_{i}+\beta_{i}\left(M R_{t}\right)+u_{i, t}
$$


Where $C R_{P, t}$ is the return of portfolio P for month t. $\alpha_{i}$ represents all the return from the Momentum portfolios that cannot be explained by the market risk factor (Vas and Absalonsen, 2014). $\boldsymbol{u}_{i, t}$ is the zero mean disturbance term. $\beta_{i}$ Measures the systematic risk. $M R_{t}$ is return on market portfolio which represents the monthly return of DSE market index and it is calculated as follows:

$$
M R_{t}=\ln \frac{M P_{t}}{M P_{t-1}}
$$

The market model has applied for the period from January 2010 to December 2016, which is the whole study period.

Alpha and Betas of portfolio are obtained by using SPSS V.22 package. Since we apply OLS method to estimate the parameters of market model, the validity of regression model is tested.

\section{RESULTS AND DISCUSSION}

\subsection{Testing Momentum Profitability in DSE Market}

At first, the normality of Momentum returns' series is tested in each of 16 strategies (results are shown in appendices A, B and C). For normally distributed series, the parametric test (one-sample t-test) is used, and nonparametric test (Kolmogorov-Smirnov- KS one sample test) is used for non-normally distributed series. Table 2 reports the average returns of the different Winners, Losers and Momentum portfolios under each of the 16 strategies described in the methodology.

Looking at the winners' portfolios on Table 2, we find 15 out of 16 strategies produce a positive return. However, only three of the profitable winners' portfolios are statistically significant at $5 \%$ level, these are: "12months/3-months strategy" that yields (3.277\%) monthly, "12-months/9-months strategy" that yields (6.941\%) monthly, and "12-months/12-months strategy" that yields (7.024\%) monthly. There is only one strategy that yields negative return among the winners' portfolios. However, this strategy is not statistically significant at $5 \%$ level. This indicates, for winner portfolios, that we have to invest in a portfolio that have longer formation period as compared with shorter formation period. Our results in terms of winner portfolios, come in favor of Momentum effect; that is past winners are achieving positive returns in the future. In this case, if investors select best performed stocks based on their returns over the past 12 months and then holds the portfolio for 3, 9, or 12 months, then they will be able to earn abnormal profits.

With regard to the losers' portfolios on table 2 , we notice that 3 out of 16 strategies produce negative returns; however, none of them is statistically significant. In addition, there are 13 losers' portfolios that yield positive returns, but only one of them is statistically different from zero (at 5\% significant level) which is "9-months/6months strategy" that yields $(0.701 \%)$ return per month. This result comes in line with Contrarian effect. Consequently, past losers are achieving positive returns in the future. In this case, if investors select worst performed stocks based on their returns over the past 9 months and then holds the portfolio for 6 months then they will be able to earn abnormal profits.

Regarding Momentum portfolios, the evidence suggests that only 3 Momentum strategies among 16 strategies yield negative returns. These strategies are: "9-months/9-months strategy", "9-months / 12-months strategy", and "12-months /12-months strategy". However, all these three strategies are not statistically significant. While the remaining 13 profitable Momentum strategies yield positive returns, but only one strategy yields significant positive return, which is "3-months/3-months strategy" with monthly return (5.38\%). This indicates that investors will be able to earn abnormal returns in case of buying high performed stocks (stocks with high returns) over the 
previous 3 months and selling low performed stocks (stocks with low returns) over the same time-period, and then holding the portfolio for 3 months.

Table-2. Momentum profitability in Damascus Securities Exchange

\begin{tabular}{|c|c|c|c|c|c|}
\hline \multirow{2}{*}{ J-month } & & \multicolumn{4}{|l|}{ K-month } \\
\hline & & 3-month & 6-month & 9-month & 12-month \\
\hline \multirow{9}{*}{ 3-month } & Winner & 0.04021 & 0.03608 & 0.04166 & 0.05607 \\
\hline & One sample t-test & 0.136 & 0.770 & 0.659 & 0.719 \\
\hline & p. value & 0.200 & 0.448 & 0.516 & 0.480 \\
\hline & Loser & -0.01362 & -0.01400 & 0.00425 & 0.02208 \\
\hline & One sample t-test & 0.150 & -0.284 & 0.067 & 0.288 \\
\hline & p. value & 0.125 & 0.779 & 0.947 & 0.776 \\
\hline & Momentum & 0.05382 & 0.05008 & 0.03741 & 0.03398 \\
\hline & One sample t-test & 2.558 & 1.441 & 0.759 & 0.566 \\
\hline & p. value & $0.017 * * \mu$ & 0.162 & 0.455 & 0.577 \\
\hline \multirow{9}{*}{ 6-month } & Winner & 0.00290 & 0.03677 & 0.02938 & 0.03421 \\
\hline & One sample t-test & 0.100 & 0.102 & 0.135 & 0.328 \\
\hline & p. value & 0.922 & 0.200 & 0.200 & 0.749 \\
\hline & Loser & -0.00555 & 0.01435 & 0.01525 & 0.02240 \\
\hline & One sample t-test & -0.343 & 0.264 & 0.183 & 0.231 \\
\hline & p. value & 0.738 & 0.796 & 0.858 & 0.821 \\
\hline & Momentum & 0.00846 & 0.02242 & 0.01413 & 0.01182 \\
\hline & One sample t-test & 0.276 & 0.579 & 0.282 & 0.232 \\
\hline & p. value & 0.787 & 0.573 & 0.783 & 0.821 \\
\hline \multirow{9}{*}{ 9-month } & Winner & 0.02636 & 0.05044 & -0.02149 & 0.01469 \\
\hline & One sample t-test & 0.931 & 0.480 & -0.151 & 0.096 \\
\hline & p. value & 0.379 & 0.646 & 0.884 & 0.926 \\
\hline & Loser & 0.00185 & 0.00701 & 0.00858 & 0.06261 \\
\hline & One sample t-test & 0.055 & 0.354 & 0.281 & 0.552 \\
\hline & p. value & 0.957 & $0.004 * * * \mathrm{c}$ & 0.062 & 0.598 \\
\hline & Momentum & 0.02451 & 0.04343 & -0.03008 & -0.04792 \\
\hline & One sample t-test & 1.748 & 0.743 & -0.269 & -0.404 \\
\hline & p. value & 0.119 & 0.482 & 0.796 & 0.698 \\
\hline \multirow{9}{*}{ 12-month } & Winner & 0.03277 & 0.07145 & 0.06941 & 0.07024 \\
\hline & One sample t-test & 0.354 & 0.468 & 0.330 & 0.367 \\
\hline & p. value & $0.018^{* *} \mu$ & 0.659 & $0.040^{* *} \mu$ & $0.011 * * \mu$ \\
\hline & Loser & 0.01404 & 0.04549 & 0.04480 & 0.07718 \\
\hline & One sample t-test & 0.220 & 0.351 & 0.316 & 0.467 \\
\hline & p. value & 0.834 & 0.740 & 0.765 & 0.660 \\
\hline & Momentum & 0.01874 & 0.02596 & 0.02461 & -0.00694 \\
\hline & One sample t-test & 0.583 & 0.433 & 0.309 & -0.079 \\
\hline & p. value & 0.585 & 0.683 & 0.770 & 0.940 \\
\hline
\end{tabular}

gnificant Momentum profits $\mu$

****, ** are $1 \%$ and $5 \%$ significant levels respectively.

Source: Outputs from processing data using SPSS V.22

The average cumulative returns of these 16 Momentum portfolios are shown graphically in Figure 1. As we can see from this figure the strategy "3-month forming/3-month holding" experience the highest returns (5.38\% per month) followed by the strategy "3-month forming/6-month holding "with monthly returns (5\%per month). 


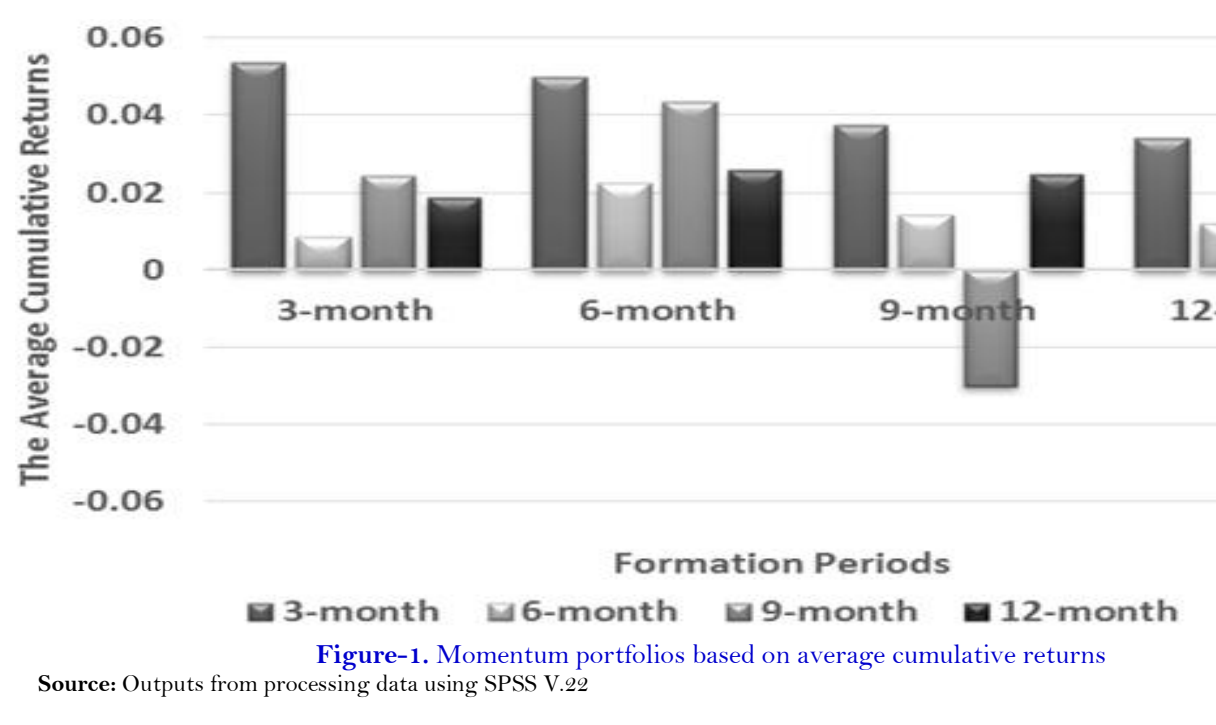

To sum up, the most profitable Momentum portfolios in DSE stock market are the strategies with a 3 month ranking period and 3 month holding period. It is worth noting that Polak and Ejaz (2012) also found that the most successful momentum strategy is "3-month forming/3-month holding" which is giving 17\% return applying on Bombay Stock Exchange (BSE). In addition, Khan et al. (2016) get the best results with "3-month forming/3-month holding" and "3-month forming/9-month holding" strategies. The finding of our study and Polak and Ejaz (2012) study do not stand with Jagadeesh and Titman (1993) who found out that "12-month forming/3-month holding" momentum strategy is more profitable. One possible explanation is that DSE and BSE stock markets are developing stock markets, while Jagadeesh and Titman (1993) conducted their study on developed stock markets.

\subsection{Testing Risk-Based Explanation of Momentum Profitability in DSE Market}

Since only one Momentum strategy "3-month forming/ 3-month holding" has reported abnormal profits, it is necessary to investigate whether there are risk-based factors behind those abnormal profits of this strategy.

Table 3 summarizes the OLS method outputs of the market model. The R-square values in the model indicate how well market return explains the returns of winner portfolios, loser portfolios, and Momentum portfolios. It can be noticed that the market model is able to explain $65.4 \%$ of the return variation in the winner portfolios. While, it explains $56 \%$ of the return variation in the loser portfolios. However, the market model does not seem to explain why Momentum profits occur.

Since the beta value (which measures the systematic risk, also known as undiversified risk) of the portfolio of past winners (0.998) is higher than the beta of the portfolio of past losers (0.905), the beta of the Momentum portfolio is positive. This means that winner portfolio appear to be riskier than loser portfolio. However, since the beta value of the Momentum portfolio is insignificant, it means that the beta values of the winner and loser portfolios are virtually the same.

With regard to alpha values, which represent all the return from the Momentum portfolios that cannot be explained by the market risk factor (Vas and Absalonsen, 2014) they are all statistically significant at $1 \%$ level, and they are positive for winner and Momentum portfolios, while negative for loser portfolios.

To sum up, market risk is unable to explain the Momentum profitability in DSE market. Similar result obtained in other markets by Jagadeesh and Titman (1993;2001); Hon and Tonks (2001); Siganos (2004); Sondergaard (2010); Al-Muhairi (2011); Kolobaric and Khatabakhsh (2011) and Vas and Absalonsen (2014). 
Table-3. Market model: Momentum strategy J3/K3

\begin{tabular}{|c|c|c|c|c|}
\hline & & \multicolumn{3}{|l|}{ Dependent variables } \\
\hline & & $\begin{array}{l}\text { Winners portfolios } \\
\text { return }\end{array}$ & $\begin{array}{l}\text { Losers portfolios } \\
\text { return }\end{array}$ & $\begin{array}{l}\text { Momentum } \\
\text { portfolios return }\end{array}$ \\
\hline \multirow{2}{*}{$\begin{array}{l}\text { Independent } \\
\text { variables }\end{array}$} & $\begin{array}{l}\text { Constant } \\
\text { Or alpha value }\end{array}$ & $\begin{array}{l}0.039 * * * \\
(0.005) \\
{[8.421]}\end{array}$ & $\begin{array}{l}-0.042^{* * *} \\
(0.005) \\
{[-8.279]}\end{array}$ & $\begin{array}{l}0.081^{* * *} \\
(0.008) \\
{[10.183]}\end{array}$ \\
\hline & $\begin{array}{l}\text { Market portfolio } \\
\text { return }\left(M R_{t}\right) \\
\text { Or Beta value }\end{array}$ & $\begin{array}{l}0.998 * * * \\
(0.082) \\
{[12.226]}\end{array}$ & $\begin{array}{l}0.905^{* * *} \\
(0.090) \\
{[10.027]}\end{array}$ & $\begin{array}{l}0.093 \\
(0.141) \\
{[0.661]}\end{array}$ \\
\hline \multicolumn{5}{|c|}{ Model Summary: } \\
\hline \multicolumn{2}{|c|}{ R Square } & 0.654 & 0.560 & 0.006 \\
\hline \multicolumn{2}{|c|}{ Durbin- Watson } & 1.772 & 2.375 & 2.068 \\
\hline \multicolumn{2}{|c|}{ F-test } & 149.477 & 100.54 & 0.437 \\
\hline \multicolumn{2}{|c|}{ P. value (F-test) } & 0.000 & 0.000 & 0.510 \\
\hline
\end{tabular}

Notes: Numbers without ( ) or [] are the coefficients. Numbers between () are standard error values, and numbers between [ $]$ are t-statistic values.

***, ** are $1 \%$ and $5 \%$ significant levels respectively.

Source: Outputs from processing data using SPSS V.22

\section{CONCLUSION}

This study investigates the profitability of Momentum strategies of 24 companies listed in Damascus Securities Exchange (DSE) market using monthly data for the period from January 2010 to December 2016. The study is also extended to investigate whether Momentum profits can be explained by the market risk.

Our methodology builds on the procedure suggested by Jagadeesh and Titman (1993). We tested 16 different Momentum strategies ( 4 formation periods $* 4$ holding periods) using full rebalancing method (or non-overlapping period) and equally weighted techniques. Under each strategy, we constructed three portfolios based on their returns during formation period: winners' portfolios (top 30\%), medium portfolios (40\%), and losers' portfolios (bottom 30\%). Based on the portfolios' returns, Momentum portfolio or "Zero-Cost Portfolio" is constructed by calculating the difference between winners' portfolios returns and losers' portfolios returns.

We find low but significant Momentum effect in DSE market. The results show that Momentum strategy is applicable for winner stock, which means that past winner stocks will continue to make profit in the next period. While for loser stocks, it is more effective to use contrarian strategy as in the next period, loser stocks will rebound and make profit after suffering from high loss. This result is similar to that of Rouwenhorst (1999) and Luxianto (2010). However, when looking at Momentum portfolios, the results show that there is only one strategy "3months/3-months strategy" that yields significant positive return of (5.38\% monthly).

Based on our results, investors in DSE market can make abnormal profits by investing in one or more of the following strategies:

1. In terms of winner portfolios, selecting the best performed stocks based on their returns over the past 12 months and then holding the portfolio for 3, 9, or 12 months.

2. In terms of loser portfolios, selecting the worst performed stocks based on their returns over the past 9 months and then holding the portfolio for 6 months.

3. Momentum strategy suggests that investors can earn abnormal returns by buying the best performed stocks and selling the worst performed stocks based on their returns over the past 3 months, and then holding this portfolio for 3 months.

The presence of Momentum effect in DSE market suggests that this market is inefficient of weak form of efficiency, which confirms the results of previous studies in this market such as Al-Ahmad (2012) and Abbas (2014). Finally, market risk appears to has no explanatory power in relation to the Momentum returns in DSE market. 
Funding: This study received no specific financial support.

Competing Interests: The authors declare that they have no competing interests.

Contributors/Acknowledgement: All authors contributed equally to the conception and design of the study.

\section{REFERENCES}

Abbas, G., 2014. Testing random walk behavior in the damascus securities exchange. International Journal of Academic Research in Accounting, Finance and Management Sciences, 4(4): 317-325. View at Google Scholar | View at Publisher

Al-Ahmad, Z., 2012. Testing the weak form efficiency of the damascus securities exchange. International Research Journal of Finance and Economics, 85: 154-165. View at Google Scholar

Al-Muhairi, M., 2011. Assessing momentum investment strategies in the U.A.E. Stock Market. PH.D Thesis, Department of Finance and Accounting, Business School, University of Portsmouth.

Annerstedt, P. and A. Schonstrom, 2006. Profitability of momentum strategies on the nordic stock market. Master dissertation. Department of Business Administration, School of Economics and Management, Lund University.

Cheng, J.W. and H. Wu, 2010. The profitability of momentum trading strategies: Empirical Evidence from Hong Kong. International Review of Economics and Finance, 19(4): 527-538. View at Google Scholar | View at Publisher

Chordia, T. and L. Shivakumar, 2006. Earnings and price momentum. Journal of Financial Economics, 80(3): 627-656. View at Google Scholar | View at Publisher

Chui, A.C.W., S. Titman and K.C.J. Wei, 2001. Momentum, legal systems and ownership structure: An analysis of Asian stock markets. Working Paper. Hong Kong Polytechnic University.

De Bondt, W.F.M. and R.H. Thaler, 1985. Does the stock market overreact? Journal of Finance, 40: 793-805. View at Google Scholar

De Bondt, W.F.M. and R.H. Thaler, 1987. Further evidence of investor overreaction and stock market seasonality. Journal of Finance, 42(3): 557-581. View at Google Scholar | View at Publisher

Griffin, J.M., X. Ji and J.S. Martin, 2003. Momentum investing and business cycle risk: Evidence from pole to pole. Journal of Finance, 58(6): 2515-2547. View at Google Scholar | View at Publisher

Habib-Ur-Rahman and H.M. Mohsin, 2012. Momentum effect: Empirical evidence from karachi stock exchange. Pakistan Development Review, 4: 449-461. View at Google Scholar

Hon, M. and I. Tonks, 2001. Momentum in the UK Stock Market. Discussion Paper, Department of Economics, University of Bristol 01/516: 1-23.

Jagadeesh, N. and S. Titman, 1993. Returns to buying winners and selling losers: Implications for stock market efficiency. Journal of Finance, 48(1): 65-91. View at Google Scholar | View at Publisher

Jagadeesh, N. and S. Titman, 2001. Profitability of momentum strategies: An evaluation of alternative explanations. Journal of Finance, 56(2): 699-720. View at Google Scholar | View at Publisher

Khan, S., F. Saddiqui, H. Ali and S.U. Khan, 2016. Momentum strategies and karachi stock exchange. Journal of Poverty, Investment and Development, 26: 51-61.

Kolobaric, A. and P. Khatabakhsh, 2011. Profitability of momentum strategies around the World. Master Dissertation, Department of Economics, Lund University.

Luxianto, R., 2010. Comparison in measuring effectiveness of momentum and contrarian trading strategy in Indonesian stock exchange. Master Thesis, Faculty of Economics. Jakarta, Indonesia.

Polak, P. and A. Ejaz, 2012. Momentum strategy and Bombay stock exchange. Modern Economy: Challenges, Trends and Prospects, 7. Retrieved from http://ssrn.com/abstract=2351678.

Rouwenhorst, K.G., 1998. International momentum strategies. Journal of Finance, 53(1): 267 -284. View at Google Scholar

Rouwenhorst, K.G., 1999. Local return factors and turnover in emerging stock markets. Journal of Finance, 54(4): 1439-1464. View at Google Scholar | View at Publisher

Siganos, A., 2004. The momentum effect on the London stock exchange. PH.D Thesis, Department of Accounting Finance \& Law, University of Stirling, London. 
Sondergaard, M.E., 2010. The momentum effect on stock markets: A Literature Review and An Empirical Study. Master Dissertation in Finance and Accounting, Copenhagen Business School- Institute of Accounting and Auditing. .

Vas, A. and K. Absalonsen, 2014. The momentum effect: An empirical study of the Oslo stock exchange. Master Dissertation in

Applied Economics and Finance, Copenhagen Business School.

\section{BIBLIOGRAPHY}

Damascus Securities Exchange Website, n.d. Retrieved from http://www.dse.sy/index.php.

\section{Appendices}

Appendix-A. Normality test of Momentum return series

\begin{tabular}{l|l|l|l}
\hline \multirow{2}{*}{ Momentum Strategies } & \multicolumn{2}{l}{ Kolmogorov-Smirnov } & Sig. \\
\cline { 2 - 4 } & Statistic & $\mathbf{d f}$ & 0.110 \\
\hline Momentum-3J3K & 0.296 & 6 & 0.200 \\
\hline Momentum-3J6K & 0.214 & 6 & 0.200 \\
\hline Momentum-3J9K & 0.211 & 6 & 0.200 \\
\hline Momentum-3J12K & 0.194 & 6 & 0.200 \\
\hline Momentum-6J3K & 0.173 & 6 & 0.100 \\
\hline Momentum-6J6K & 0.299 & 6 & 0.200 \\
\hline Momentum-6J9K & 0.254 & 6 & 0.200 \\
\hline Momentum-6J12K & 0.186 & 6 & 0.200 \\
\hline Momentum-9J3K & 0.225 & 6 & 0.077 \\
\hline Momentum-9J6K & 0.308 & 6 & 0.110 \\
\hline Momentum-9J9K & 0.296 & 6 & 0.200 \\
\hline Momentum-9J12K & 0.222 & 6 & 0.200 \\
\hline Momentum-12J3K & 0.182 & 6 & 0.200 \\
\hline Momentum-12J6K & 0.181 & 6 & 0.123 \\
\hline Momentum-12J9K & 0.291 & 6 & 0.200 \\
\hline Momentum-12J12K & 0.205 & 6 & \\
\hline Sorcerod & & \\
\hline
\end{tabular}

Source: processed data using SPSS V.22

Appendix-B. Normality test of winner return series

\begin{tabular}{l|l|l|l}
\hline \multirow{2}{*}{ Winners Strategies } & \multicolumn{2}{l}{ Kolmogorov-Smirnov } & \multicolumn{2}{l}{ Sig. } \\
\cline { 2 - 4 } & Statistic & $\mathbf{d f}$ & 0.024 \\
\hline Winner-3J3K & 0.346 & 6 & 0.200 \\
\hline Winner-3J6K & 0.258 & 6 & 0.063 \\
\hline Winner-3J9K & 0.315 & 6 & 0.200 \\
\hline Winner-3J12K & 0.155 & 6 & 0.134 \\
\hline Winner-6J3K & 0.287 & 6 & 0.033 \\
\hline Winner-6J6K & 0.336 & 6 & 0.034 \\
\hline Winner-6J9K & 0.335 & 6 & 0.200 \\
\hline Winner-6J12K & 0.177 & 6 & 0.200 \\
\hline Winner-9J3K & 0.211 & 6 & 0.200 \\
\hline Winner-9J6K & 0.245 & 6 & 0.200 \\
\hline Winner-9J9K & 0.268 & 6 & 0.200 \\
\hline Winner-9J12K & 0.252 & 6 & 0.018 \\
\hline Winner-12J3K & 0.354 & 6 & 0.055 \\
\hline Winner-12J6K & 0.320 & 6 & 0.040 \\
\hline Winner-12J9K & 0.330 & 6 & 0.011 \\
\hline Winner-12J12K & 0.367 & 6 & \\
\hline Source: processed data using SPSS V.20 & & & \\
\hline
\end{tabular}

Source: processed data using SPSS V.22 
Appendix-C. Normality test of loser return series

\begin{tabular}{l|l|l|l}
\hline \multirow{2}{*}{ Losers Strategies } & \multicolumn{2}{l}{ Kolmogorov-Smirnov } & Sig. \\
\cline { 2 - 4 } & Statistic & $\mathbf{d f}$ & 0.045 \\
\hline Losers-3J3K & 0.326 & 6 & 0.163 \\
\hline Losers -3J6K & 0.278 & 6 & 0.200 \\
\hline Losers -3J9K & 0.235 & 6 & 0.200 \\
\hline Losers -3J12K & 0.252 & 6 & 0.200 \\
\hline Losers -6J3K & 0.178 & 6 & 0.200 \\
\hline Losers -6J6K & 0.230 & 6 & 0.200 \\
\hline Losers -6J9K & 0.263 & 6 & 0.200 \\
\hline Losers -6J12K & 0.176 & 6 & 0.200 \\
\hline Losers -9J3K & 0.204 & 6 & 0.001 \\
\hline Losers -9J6K & 0.419 & 6 & 0.031 \\
\hline Losers -9J9K & 0.338 & 6 & 0.126 \\
\hline Losers -9J12K & 0.290 & 6 & 0.200 \\
\hline Losers -12J3K & 0.268 & 6 & 0.200 \\
\hline Losers -12J6K & 0.183 & 6 & 0.200 \\
\hline Losers -12J9K & 0.183 & 6 & 0.200 \\
\hline Losers -12J12K & 0.199 & 6 & \\
\hline Source: procesed data & & & \\
\hline
\end{tabular}

Source: processed data using SPSS V.22 